DOI: 10.12957/demetra.2015.16044

\title{
Hábitos alimentares e sociabilidade no horário de almoço de estudantes universitários
}

\section{Food habits and sociability at lunch time of university students}

Niara Ulhoa Faria'

Ana Elisa Madalena Rinaldi ${ }^{1}$

Mônica Chaves Abdala²

1 Universidade Federal de Uberlândia. Curso de Graduação em Nutrição, Faculdade de Medicina. Uberlância-MG, Brasil.

${ }^{2}$ Universidade Federal de Uberlândia. Faculdade de Artes, Filosofia e Ciências Sociais, Departamento de Ciências Sociais. UberlânciaMG, Brasil.

Correspondência / Correspondence Mônica Chaves Abdala

E-mail: monicabdala@hotmail.com

\section{Resumo}

$\mathrm{O}$ ato de se alimentar, além de satisfazer as necessidades fisiológicas, envolve sentimentos, emoções, memórias, desejos que influenciam nas escolhas alimentares, podendo também identificar grupos e locais geográficos. O objetivo deste trabalho foi identificar os hábitos e escolhas alimentares de universitários no horário do almoço e o modo como se comportam frente a elas. Foi utilizada metodologia qualitativa, por meio de entrevistas aplicadas com participação de estudantes voluntários no campus Umuarama da Universidade Federal de Uberlândia-MG. Os pontos abordados no estudo foram o número diário de refeições, a substituição de refeições completas por refeições rápidas (lanches), as preferências alimentares e a relação entre as escolhas alimentares e a companhia durante as refeições. Concluímos que não há a referida substituição no horário do almoço e que as companhias, o ambiente, a duração e as escolhas alimentares são fatores que interferem no valor nutricional da alimentação dos entrevistados, sinalizando a importância de aspectos culturais e sociais do comer.

Palavras chave: Almoço. Comportamento Alimentar. Sociabilidade.

\section{Abstratct}

Eating is far beyond satisfying the bodily needs; it involves feelings, emotions, memories, desires that influence food choices and the companies to make a meal, and may also determine a 
group, a place. This article aimed to identify habits and eating choices of university students at lunch time and how they behave then. Qualitative methodology was used, by means of interviews applied with aleatory participation of volunteers at the Umuarama campus from Federal University of Uberlândia. We asked about replacement of a meal define as genuine for a snack at lunch time, which were food preferences, the number of meals were made per day by university students and the relationship between food choices and to make the meal alone or accompanied. We conclude that there is no replacement at lunchtime and that the companies, the environment, the duration and food choices are factors that affect the nutritional value of food of respondents, indicating the importance of cultural and social eating aspects.

Key words: Lunch. Feeding Behavior. Sociability.

\section{Introdução}

Alimentar-se não se restringe a satisfazer as necessidades nutricionais do corpo. Para Fischler, ${ }^{1}$ falar de comida não é tratar exclusivamente de nutrição; comida não é somente nutrientes. $\mathrm{O}$ ato de se alimentar significa também criar práticas e atribuir significados ao que a pessoa está incorporando a si. $^{2}$

A comida pode determinar um grupo, um lugar, servindo como marcador de identidade ligado a significados. Além disso, envolve também sentimentos, emoções, memórias e desejos que influenciam diretamente as escolhas alimentares e as companhias às refeições. Desta forma, o que se come, com quem se come e onde se come marcam os padrões socialmente estabelecidos, e quando se percebem mudanças nos hábitos alimentares fica claro que esses padrões sofreram alterações que se relacionam a reformulações dos comportamentos.

Desse modo, com quem se come pode interferir diretamente na seleção do que comer e de onde comer, pois a "desestruturação" da refeição e sua ligação com a liberdade de escolha estão intimamente ligadas ao coletivo. Entende-se que a responsabilidade pela opção do que se vai comer é do coletivo e não do comedor, pois apesar de construir individualmente suas refeições, nunca o faz com total liberdade. ${ }^{3}$

Objetiva-se, então, identificar os hábitos e escolhas alimentares dos jovens universitários no horário do almoço na Universidade Federal de Uberlândia, no campus Umuarama, visando conhecer as preferências alimentares e o modo como se comportam frente a elas, relacionando-as ao fato de fazerem a refeição sozinhos ou acompanhados. 
Observar aspectos sociais que envolvem as escolhas alimentares relacionando-as a aspectos nutricionais é a singularidade deste estudo. São pouco numerosas as pesquisas realizadas sobre alimentação de universitários que ora focam na perspectiva nutricional, ora centram em aspectos sociais, apenas apontando mudanças nos hábitos alimentares, sem considerar questões próprias do campo da Nutrição. Pretendemos, desse modo, contribuir para um efetivo diálogo entre Ciências Sociais e Nutrição, o que tem constituído a preocupação central de vários estudiosos, ${ }^{4,5}$ refletindose nos grupos de trabalhos de congressos das duas áreas*.

\section{Estudos sobre alimentação de universitários}

Realizou-se levantamento bibliográfico de publicações sobre alimentação de universitários, focado nas pesquisas que não restringem suas análises ao campo da Nutrição, incorporando aspectos sociais do comer.

Iniciamos com o artigo "A desconstrução de hábitos alimentares entre jovens universitários", em que Araujo e Abdala ${ }^{6}$ propuseram estudar os hábitos alimentares de estudantes na mesma universidade onde realizamos nossa pesquisa, a Universidade Federal de Uberlândia (UFU), em outro campus, o Santa Mônica. Buscando conhecer em que consiste a refeição feita pelos estudantes no horário do almoço, como e com quem ela é feita, o objetivo do estudo foi apreender se os entrevistados seguem ou reformulam os horários, o conteúdo e a forma de se comportarem durante essa refeição. Observou-se também se há substituição do almoço (comida dita "de verdade", que consiste em arroz, feijão, carne e acompanhamentos) por um snack ou lanche. Outro objetivo foi analisar os significados do horário do almoço para esses estudantes, assim como confrontar seus comportamentos e concepções sobre o almoço ideal e real.

Trata-se de pesquisa qualitativa com emprego da técnica de entrevista semidiretiva e observação de campo para a coleta dos dados. Foram realizadas 30 entrevistas precedidas por questões relativas ao perfil demográfico e socioeconômico. Durante as observações preliminares, as autoras notaram o movimento em alguns estabelecimentos de alimentação escolhidos devido à facilidade de acesso e por serem bastante frequentados pelos estudantes, dentre eles o Restaurante Universitário (RU), uma cantina que trabalhava com venda de lanches dentro da universidade e outros dois que serviam "comida de verdade" no almoço e lanches durante o dia, um dentro e o outro nas proximidades do campus.

Em sua observação de campo, as autoras descrevem que grande parte dos estudantes que almoçava na UFU estava acompanhada, porém o número de acompanhantes não era fixo,

* A Reunião Brasileira de Antropologia (RBA), por exemplo, desde o ano 2000, congrega profissionais de diversas áreas em torno do tema Antropologia da Alimentação. Vale destacar que o GT "Diálogos no campo da Antropologia da Alimentação”, durante a 29a RBA (2014), inspirou este dossiê da Demetra. 
dependendo do local em que a refeição ocorria. Em relação aos custos, o almoço mais barato foi no $\mathrm{RU}$, e o gasto com lanches se equiparou ou ultrapassou o valor dispendido com comida. Um fator que se destacou no horário do almoço foi a pressa para comer; outro dado marcante foi a diferença do que se come e dos modos à mesa. Não foi observada uma estrutura fixa e compartilhada de comportamentos à mesa, e notou-se que a companhia é muito valorizada pelos que almoçam.

$\mathrm{Na}$ análise das entrevistas, foi destacado que é unânime o relato quanto ao tempo ou a falta dele para esta refeição. Os entrevistados demonstraram perceber a rapidez com que comem, justificando-a por força do hábito adquirido, pelo pouco tempo disponível para um grande número de atividades realizadas e também pela necessidade de dar lugar para outros comerem. A maioria tem preferência pela "comida de sal", denominação dada pelos entrevistados ao que as autoras chamam de "comida de verdade". O local onde fazem a refeição é escolhido pela praticidade ou pela bolsa, quando se trata do RU. A maioria dos universitários não faz a refeição do horário do almoço sem companhia, mas às vezes eles realizam diferentes opções (uns almoçam, enquanto outros tomam lanches) e/ou diferentes modos de se portar à mesa. As autoras constataram, ainda, que há um esforço dos entrevistados para manter os laços sociais na universidade, relacionado à concepção de almoço ideal, aquele feito em casa com a família.

Araujo e Abdala ${ }^{6}$ concluem, com base em Rial, ${ }^{7}$ que as mudanças na alimentação contemporânea não caracterizam uma ausência de estrutura, mas significam novas estruturas construídas de acordo com as necessidades e o contexto vivenciado no momento. Concluem também que os universitários entrevistados, de modo geral, mantêm o costume da refeição no horário habitual de almoço mesmo quando têm um curto intervalo e mesmo que este signifique que a refeição vai ser feita entre 15 e 20 minutos. Na organização do tempo, valorizam estar acompanhados, mais do que o que vão comer. Portanto, o modo de estruturar as refeições indica mudanças, mas no plano das representações o modelo ideal das refeições permanece sendo o da casa, referência quanto à comida, ao horário ou ao fato de procurar uma companhia. Isso mostra que, lentamente, as definições e códigos de tempo e espaço de casa e rua estão sendo reconstruídos e vêm sofrendo alterações significativas, em que o limite entre esses dois espaços tende a se desfazer.

E por fim, as autoras afirmam que há a necessidade de projetos de políticas públicas que proponham oferta de melhores condições para se alimentar e espaço para permanecer após as refeições, a fim de fortalecer e (re)criar laços de sociabilidade entre os universitários.

Dois outros artigos que tratam a alimentação dos universitários em abordagens que não se concentram em aspectos nutricionais interessam aos objetivos desta pesquisa. O primeiro deles, "Comportamento alimentar em moradia estudantil: um espaço para promoção da saúde", ${ }^{8}$ teve como objetivo descrever qualitativamente as práticas alimentares de estudantes residentes em moradia universitária e analisar os padrões de individualidade/coletividade associados a essa 
prática. Para a metodologia empregada, a amostra foi retirada do universo de 253 residências na moradia estudantil que abrigavam 825 estudantes de graduação e pós-graduação no município de Campinas-SP, sendo as residências participantes sorteadas aleatoriamente. Foram utilizadas as técnicas de observação participante e entrevistas estruturadas, e as informações colhidas foram sobre a alimentação do entrevistado nas últimas 24 horas (recordatório), padrão de compra de alimentos da casa, representação de alimentação saudável e comportamentos referentes à comensalidade.

Dentre os resultados encontrados na pesquisa, destacam-se aqueles referentes ao almoço, que foi a refeição considerada pelas autoras de melhor qualidade: $72 \%$ fazem um almoço completo (composto por alimentos construtores, energéticos e reguladores, com presença obrigatória de hortaliças) ${ }^{* *}$. Isso se deve, sobretudo, ao fato de $63 \%$ dos entrevistados terem feito esta refeição no restaurante universitário. Sobre coletividade e comensalidade, em relação às compras, $69 \%$ demonstraram comportamento individual, 24\%, misto, e 7\%, coletivo. Quarenta e três por cento relataram que o fato de comer acompanhado altera a alimentação de modo positivo, $37 \%$ disseram que altera em algumas ocasiões e 20\%, que comer em companhia não altera a alimentação.

As autoras mostraram que comer é um fato social interligando o social e o individual, o físico e o psíquico - portanto, o comportamento alimentar certifica um contrato social de identidades. Compartilhar a comida é então um ritual de vinculação social que afirma a identidade comum de um grupo, daí a importância de escolher com quem se come.

No artigo "Hábitos alimentares dos estudantes universitários: um estudo qualitativo", 9 o objetivo foi identificar os hábitos alimentares de estudantes universitários e como estes lidam com as possíveis mudanças advindas no ingresso da faculdade. Esta pesquisa qualitativa utilizou para a coleta dos dados questionário semiestruturado em que as questões foram separadas em cinco aspectos (café da manhã, almoço, jantar, lanches alternativos e finais de semana) e em cada aspecto foi questionado sobre o que se come, quando, onde, com quem, quando e quanto tempo se gasta para realizar cada refeição. Foram realizadas 20 entrevistas (12 mulheres e 8 homens) com alunos entre 18 e 38 anos da Universidade Federal de Mato Grosso do Sul (UFMS) no campus de Campo Grande. Os resultados encontrados no aspecto do almoço foram: falta de tempo; almoço realizado em conjunto quando feito em casa e sozinho quando feito em outros locais; a percepção de comer fora é vista como fugir dos padrões preestabelecidos, ou seja, alimentação não saudável e comer em casa, um ato saudável; em relação aos alimentos consumidos, são mais citados arroz, feijão, salada, ovos, macarrão, mandioca, carne bovina e de aves e peixes, as verduras e legumes são citadas com menos frequência; e na escolha do que vão tomar, são mais adeptos a sucos naturais,

** As autoras consideram um almoço completo com base nos critérios usados por Gambardella et al.: ${ }^{15}$ que contém alimentos fonte de proteína (construtores) como o feijão, carnes ou ovos; energia (energéticos) compostos por cereais e tubérculos como arroz, massas em geral e batata; e vitaminas, minerais e fibras (reguladores) por frutas e hortaliças. 
com menos preferência pelo refrigerante, e dependendo dos recursos financeiros, preferem água. Concluiu-se, então, que entre esses universitários a disponibilidade de tempo, recursos financeiros, lugar, variedade de alimentos e qualidade dos produtos são fatores determinantes para as escolhas alimentares; comer fora de casa é sinônimo de não saudável; quando há a substituição do almoço por um sanduíche ou salgado, este não é considerado uma refeição, somente um lanche ou uma ação imediata para amenizar a fome.

Além dos estudos acima abordados, outra pesquisa analisa hábitos alimentares com pessoas da Universidade Federal de Uberlândia, embora não se restrinja aos universitários: Castro e Abdala, ${ }^{10}$ em "Televisão no momento das refeições", tratam da importância social da refeição, colocando-a como propiciadora de sociabilidade e ritualização, e observam as mudanças referentes ao hábito alimentar na contemporaneidade, visto que cada vez mais a televisão está presente nesse momento.

Os objetivos da pesquisa foram observar se a televisão desempenha papel significativo nas relações sociais familiares no momento das refeições; observar se seu uso ocorre e é visto de maneira diferente segundo o perfil socioeconômico da família e diferentes faixas etárias, além de analisar se esse momento continua a ser de refeição tida como momento de sociabilidade, ritualização e estruturação.

A metodologia empregada foi a qualitativa, utilizando questionário e entrevista semidiretiva. O local do estudo foi o campus Santa Mônica da Universidade Federal de Uberlândia (UFU) e a amostra era composta por estudantes, professores, funcionários, terceirizados que prestam serviços, funcionários de estabelecimentos comerciais e agências de serviços.

Em seus resultados e discussão, elas relatam que foram entrevistadas 38 pessoas, sendo 16 alunos, seis funcionários, seis professores da UFU e 10 prestadores de serviços (englobando funcionários de empresas terceirizadas e agências que prestam serviços, e também comerciantes) - 14 homens e 24 mulheres, dos quais 65\% solteiros. Observaram que 47\% moravam em domicílios com famílias nucleares; as demais eram pessoas que moravam apenas com os filhos, e em menor quantidade, as que moravam com familiares e também com não aparentados.

Em relação à refeição considerada principal, 65\% dos entrevistados realizam o almoço na metade do dia, o que não foi relacionado à sociabilidade, mas a uma questão alimentar e nutricional apontada por $63 \%$ das entrevistas. Um segundo fator, apontado por $17 \%$ das pessoas, está ligado ao tempo ou à falta dele e ao desejo de tranquilidade. E o terceiro fator, indicado por $17 \%$ das pessoas, foi estar com a família.

Quanto ao jantar, notou-se que este não tem muita importância para os entrevistados, sendo sua realização variável. Algumas vezes não é realizado, às vezes comem algo antes de dormir, 
mas não necessariamente a "janta”, ou ainda afirmam que o jantar "engorda” ou é pesado para quem tem suas atividades estendidas até mais tarde. A preocupação com a comida pesada no jantar e com o fato de engordar foi relatada principalmente entre as mulheres (37\%); 39\% dos entrevistados costumam jantar sozinhos; 23,6\% o fazem às vezes sozinhos ou acompanhados; e $36 \%$ acompanhados na maioria das vezes por familiares.

Levando em consideração a refeição e a televisão, do total de entrevistados (38), apenas 37\% não têm o hábito de jantar em frente a TV; $5 \%$ relatam não ver TV, entendendo-a como algo que atrapalha a refeição de todos; $8 \%$ relataram a refeição como um momento silencioso; e entre aqueles que assistem TV, $53 \%$ conversam enquanto comem e tratam de outros assuntos distintos dos veiculados na televisão.

As autoras concluíram que, no grupo de entrevistados, o sentido de refeição principal está ligado à saúde e energia, mais do que à socialização, levando então o jantar a aparecer pouco nos relatos como refeição principal. Há novas formas de estruturação, ritualização e significação da alimentação se adaptando às necessidades. O jantar pode não ser uma refeição que tenha função sociabilizadora e de ritualização, mas as pessoas constroem momentos que equivalem ao do jantar em outras situações do cotidiano. E a TV em si não impossibilita a socialização e a ritualização nas refeições, e sim o uso que se faz dela. A estrutura das refeições e o tempo gasto com elas se modificam, sinalizando mudanças, mas ainda há a percepção de alimentação ideal como aquela feita em casa, seja quanto à comida, ao horário ou à companhia.

O trabalho de Castro e Abdala ${ }^{10}$ tem relevância para esta pesquisa, pois diz respeito aos hábitos alimentares de pessoas da universidade, incluindo os de estudantes. Embora o jantar e a TV não tenham sido diretamente explorados no presente estudo, a abordagem do jantar remete à citação indireta ao almoço, sua importância do ponto de vista nutricional e também da sociabilidade.

A pesquisa de Alves e $\mathrm{Boog}^{8}$ foi realizada em moradia estudantil, o que difere desta proposta, que é a refeição feita dentro e nos arredores do campus Umuarama da UFU. No entanto, mostra-se relevante por deixar clara a importância do comer acompanhado influenciando a opção alimentar.

No trabalho de Borges e Filho, ${ }^{9}$ o aspecto da mudança de hábitos vinda com o ingresso na universidade, reunindo vários fatores que interferem na escolha alimentar de estudantes, se torna relevante à nossa proposta.

A pesquisa de Araujo e Abdala ${ }^{6}$ se faz importante por buscar conhecer em que consiste a refeição feita no horário do almoço, como e com que ela é feita, o que para a nossa proposta se faz relevante por nos nortear nos aspectos que, assim como elas, queremos observar. 


\section{Métodos}

Foi utilizada metodologia qualitativa, por entender que esta permite maior profundidade na compreensão do objeto e permite alcançar melhor as peculiaridades do grupo, assim como apreender processos de mudança em curso, recorrendo à observação e à coleta de depoimentos ${ }^{11}$. Dessa forma, o número de entrevistas não foi fator determinante para a opção adotada nesta pesquisa.

Os estudantes do campus Umuarama da UFU foram convidados a participar como voluntários durante um estudo de campo exploratório realizado com o objetivo de observar quais eram os estabelecimentos mais frequentados por eles dentro e no entorno do campus, assim como suas escolhas e comportamentos alimentares no horário do almoço, em especial se estavam ou não acompanhados.

Os universitários foram abordados aleatoriamente pela entrevistadora no horário do almoço, na entrada ou saída dos estabelecimentos onde as refeições eram realizadas. Quando aceito o convite, os objetivos da pesquisa eram elucidados e o participante assinava o Termo de Compromisso Livre e Esclarecido. As entrevistas foram gravadas. Uma vez concluídas, foram transcritas e analisadas.

Foram observados três estabelecimentos dentro da universidade, sendo uma lanchonete, um restaurante/lanchonete e o Restaurante Universitário. Nos arredores, seis restaurantes e um carrinho de rua.

Para elaboração do roteiro da entrevista, tomou-se como base o instrumento Diagnóstico das Práticas e Comportamento Alimentares, ${ }^{12}$ no qual estão previstas algumas opções de respostas que não foram lidas para o entrevistado, mas apenas serviram para direcionar a entrevistadora quando percebia que não respondiam ou não compreendiam a questão.

O roteiro aplicado continha questões sobre quantas refeições eram realizadas por dia; que tipo de alimentos eram escolhidos para essas refeições; em qual momento do dia era realizado o almoço; qual a duração (em tempo) do almoço, se o entrevistado considerava esse tempo suficiente e por que; em que local costumava almoçar e por que escolhia esse local; se no horário do almoço geralmente estava acompanhado, com quem, quantas pessoas e qual o motivo que o levava a almoçar em grupo e se não, por que almoçava sozinho; normalmente almoçava em pé (parado ou andando) ou sentado (em mesa e cadeira ou outro local - qual); a descrição da composição do prato de almoço; se o participante realizava o jantar e a descrição do que comia nesse horário.

A aplicação da entrevista foi precedida de questões demográficas e socioeconômicas que contemplaram sexo, idade, naturalidade, nacionalidade; tempo de residência em Uberlândia; descrição da cor ou raça; estado civil; com quem mora (ou divide residência) e quantas pessoas; se tem renda própria, se não tem, qual a renda da família; qual o curso, o período que estava cursando e o turno. 


\section{Resultados e discussão}

Foram aplicadas 20 entrevistas, sendo $65 \%$ realizadas com universitários do sexo feminino e 35\% do sexo masculino. Os estudantes cursavam Agronomia (3), Medicina Veterinária (2), Enfermagem (2), Psicologia (5), Zootecnia (1), Nutrição (2), Engenharia Ambiental (1), Medicina (2), Odontologia (2), todos oferecidos em período integral. Todos os participantes são brasileiros e a faixa etária declarada foi de 18 a 27 anos. Somente um aluno não declarou a idade. Em relação ao estado civil, todos se declararam solteiros, embora um dos entrevistados tenha afirmado que "mora com companheira e filho"; 70\% dos entrevistados moram com família (com pais e irmãos) e os outros 30\% se dividem entre morar em república, com parentes/amigos e sozinhos.

As principais diretrizes alimentares para a população brasileira destacam: a) a importância dos alimentos in natura ou minimamente processados, como hortaliças, frutas, carnes, arroz, feijão e leite representarem a base da alimentação - aproximadamente $85 \%$ de todos os alimentos diariamente; b) a concentração de $90 \%$ das calorias diárias serem consumidas nas três principais refeições - desjejum, almoço e jantar; c) a presença de hortaliças (legumes e folhas) no almoço e jantar, alternando a forma de preparo - crua, cozida, refogada; d) o consumo reduzido de produtos alimentícios processados e ultraprocessados; e) a realização de refeições em conjunto com outras pessoas, em ambientes calmos, sentado à mesa para que seja possível prestar atenção no que se come. ${ }^{13}$

Quando questionamos quantas refeições são feitas por dia, obtivemos resultados variados. Entre os entrevistados, 25\% dizem fazer quatro refeições; 20\%, três refeições; e 15\% entre três ou quatro refeições diárias. Dez por cento dos estudantes realizam uma e $5 \%$ realizam seis refeições diárias.

Em relação a quais são essas refeições, percebemos que todos realizam o almoço e $60 \%$ realizam o jantar. Entre as outras refeições relatadas aparecem o café da manhã, realizado por $60 \%$ dos entrevistados; o lanche da manhã, por 15\%; lanche da tarde, por $80 \%$; o lanche à noite substituindo o jantar, por 30\%; e o lanche da noite, que corresponde à ceia, por $10 \%$.

Percebemos que entre os entrevistados que relataram fazer apenas uma refeição, esta era o almoço; no entanto, quando responderam, ao final da entrevista, à pergunta sobre o jantar, afirmaram que faziam um lanche. Portanto, fica claro que consideraram refeição apenas quando estão presentes o arroz e feijão, o prato base da alimentação do brasileiro. Borges e Filho ${ }^{8}$ afirmam que quando há substituição do almoço por um sanduiche ou salgado, este não é considerado uma refeição, somente um lanche ou ação imediata para amenizar a fome. Mostram, desse modo, que é comum entre jovens universitários considerar como refeição apenas as ocasiões em que consomem o prato base ou a "comida de sal". 
O conteúdo escolhido para as refeições varia bastante de acordo com a vontade, a preferência e o que cada um tem disponível para comer e para comprar em cada uma delas. No café da manhã, $45 \%$ optam por alimentos como pão de queijo, pão, café puro e leite, à exceção de um entrevistado, que afirma comer o que sobrou do jantar do dia anterior. O lanche da manhã foi citado por apenas um entrevistado que costuma consumir bolachas ou frutas neste horário. No almoço, o arroz, feijão, carne e salada se destacaram em $80 \%$ das respostas; apenas uma pessoa afirmou comer salgado ou sanduíche nesse horário, e outras duas substituem o almoço por salgado apenas quando não há tempo. No lanche da tarde, $75 \%$ disseram consumir o pão com manteiga, presunto e queijo ou só com queijo, seguido do café preto, salgados e frutas. Já no jantar, arroz, feijão, carne e salada são apontados por 40\%, mas também são comuns as substituições por sanduíches e salgados para $60 \%$ dos entrevistados. Nesses casos, o lanche à noite pode ser feito com pão, leite, suco e macarrão instantâneo. Por fim, quando questionados quais eram as refeições feitas durante o dia, o lanche da noite/ceia foi citado, mas não foi relatado nenhum alimento consumido nesse momento.

As respostas nem sempre especificavam as escolhas alimentares nas refeições; algumas foram vagas, como a que segue:

Nossa, pergunta difícil... procuro alimentos mais saudáveis, mais nem sempre é possível, principalmente aqui na faculdade onde a disponibilidade é, não favorece (Entrevistada 11).

Galante, Galisa \& Ribeiro ${ }^{14}$ afirmam que uma alimentação equilibrada "[...] não consiste apenas no consumo de alimentos que contenham os nutrientes necessários ao indivíduo, mas também no fato dessa combinação ser agradável e apropriada ao seu estilo de vida”. O método qualitativo para planejar e analisar um cardápio e para que este seja equilibrado é perceber se contém pelo menos um alimento de cada grupo (considerando que estes grupos são: construtores; reguladores e energéticos) em todas as refeiçõesrealizadas. ${ }^{14,15}$

Quando analisamos os alimentos citados como escolhidos pelos entrevistados para suas refeições, levando em consideração os critérios descritos acima, fica claro que as escolhas alimentares destes universitários ao longo do dia, de modo geral, nem sempre contemplam todos os grupos alimentares. Entretanto, analisando apenas o almoço, como a maioria dos entrevistados relata consumir arroz, feijão, carne e salada, uma análise qualitativa não indicaria prejuízo no valor nutricional, pois conseguem nesta refeição contemplar os três grupos.

O horário em que os estudantes almoçam varia de acordo com a disponibilidade de tempo para realizarem as refeições, tais como o tempo entre o término da aula no período da manhã e o início da aula no período da tarde. Desta forma, houve estudantes que relataram almoçar às 10:30 horas (neste horário o Restaurante Universitário já está servindo o almoço; os demais restaurantes costumam iniciar seus serviços por volta das 11horas) até às 14 horas; porém $30 \%$ 
realizam o almoço às 12 horas.

As mesmas variáveis acima indicadas influenciam a duração do almoço, de 10 a 50 minutos, com 35\% relatando durar 20 minutos. O tempo declarado é considerado como suficiente em 75\% das entrevistas. Os que permanecem mais tempo afirmam que é satisfatório para comer e ainda conversar com os amigos, ou também para comer devagar, mastigar bem e ficar satisfeito. Entre os que ponderam ser tempo suficiente, encontram-se também aqueles que afirmam comer pouco ou rapidamente. Porém, aqueles que acham a duração insuficiente contrastam com as ocasiões em que se tem um tempo maior para comer, ou se queixam de haver tanta coisa para fazer que acabam reduzindo o período de almoço e comendo rápido para conseguir realizar as outras atividades, ou simplesmente alegam que o tempo é curto e têm que comer rápido.

Os locais onde almoçavam estavam dentro do campus e arredores, sendo o Restaurante Universitário (RU) o mais citado (70\%). Os outros locais de almoço mencionados foram as lanchonetes dentro do campus, restaurantes do entorno e em casa, quando possível. A justificativa para a escolha do local foi bastante ampla, desde o fato de serem bolsistas do RU, preço, comida balanceada, disponibilidade de tempo, localidade, proximidade, até variedade de preparações oferecidas.

A maioria dos entrevistados (55\%) relatou estar acompanhada no horário do almoço e apenas $10 \%$ disseram não estar acompanhados; 20\% afirmaram geralmente estar acompanhados e 15\% estar mais sozinhos que acompanhados. A respeito de quem eram essas companhias, as respostas mais citadas foram colegas de turma e amigos da faculdade da mesma sala. Quanto ao número de pessoas que formavam esses grupos para o almoço, foram obtidas respostas variadas, mas nenhuma se destacou com maior número de repetições, podendo variar de duas a 10 pessoas.

Entre os 15 universitários que realizam o almoço acompanhados ou a maioria das vezes acompanhados, apenas três fazem opção por comer salgados; todos os demais comem preparações como arroz, feijão, carne e salada no almoço. Entre os cinco que afirmaram comer sozinhos ou mais sozinhos que acompanhados, dois optam por comer arroz, feijão, carne e salada, de um modo geral, e os outros optam por salgados para o almoço. Portanto, pode-se perceber que quando estão acompanhados, buscam uma refeição dita completa, não substituindo a refeição por um lanche rápido ou snack, e quando estão sozinhos, acabam escolhendo a opção mais rápida e justificam isso muitas vezes pela falta de tempo por ter trabalhos, provas ou até mesmo aula em um intervalo pequeno de tempo.

Os motivos que levaram esses estudantes a fazer a refeição em grupo são diversos, podendo variar desde não gostarem de se sentir sozinhos, a considerar este como um horário de descontração, 
ou continuar a discussão sobre trabalhos, ou ainda a proximidade por estarem na mesma turma e cursarem as mesmas disciplinas no período da manhã e tarde. Em algumas falas, ficam claros esses motivos:

Hum... num sei, pra mim não me sentir sozinha... sei lá. (Entrevistada 12).

Ah eu não gosto de almoçá sozinha não... acho muito triste! (Entrevistada 14).

Ou ainda:

Que a gente conversa, interage, é um, um momento também de lazer, porque cê coloca o papo em dia, vai conversano, distrai mesmo a mente e come, né? (Entrevistada 15).

Quanto às motivações para almoçarem sozinhos também foram variadas, como não encontrar ninguém depois da aula; a fila do RU ficar muito grande e não ser possível esperar com os amigos; alguns dias não ter aula com os amigos de sala ouos horários das aulas serem diferentes; ou simplesmente falta de companhia. Alguns desses motivos ficam evidentes nas falas:

Às vezes porque eu tenho que fazer alguma coisa e eles não, ou eles têm que fazer alguma coisa, ou a gente desencontra aí eu vô e almoço sozinha. (Entrevistada 5).

Não sei, tempo, pressa... acho mais prático... hãa... não tê que, não espero ninguém assim, vô e almoço sozim. (Entrevistado 7).

Todos os entrevistados relataram fazer o almoço sentados em cadeira com mesa, fato também notado por Abdala ${ }^{16}$ "[...] come-se de preferência à mesa, e não em pé como os americanos". A exceção foi uma participante que relatou fazer o almoço sentada e descreveu que quando almoça salgado essa situação se modifica:

Numa mesa, cadera, às vezes num tem mesa não, mais assim, quando é num restaurante tem mesa e a cadera. Assim quando é salgado às vezes é andano. É, com um monte de gente em volta, conversando, gritando, falando e você fala, conversa e não engole direito, mastiga de um jeito qualquer, desse jeito. (Entrevistada 3).

Ah, ué! Aqui na UFU na mesa, né, normal. Mais em casa é sempre no sofá. (Entrevistada 9).

A composição do prato para 70\% é arroz, feijão, carne e salada; alguns descreveram que verdura comiam ou preferiam e se consumiam sobremesa. Os que optavam pelo salgado e refrigerante (30\%) relataram o que geralmente consomem no almoço e se há diferença com o que consumiram no dia da entrevista. 
Geralmente, é, arroz, feijão, um tipo de carne, sempre tem, muito raro não ter salada né, vegetais folhosos e alguns legumes. Hoje pela carência de tempo e muito conteúdo pra estudar pra prova que eu tenho daqui um dia, dois dias, eu almocei dois salgados e um refrigerante diet, zero. (Entrevistada 11).

Bom, eu sempre assim, não sou muito de comer arroz, carboidrato não é muito minha praia tanto assim, tô aprendendo agora pra comer mais integral então eu ponho um pouco mais, mais uma medida assim uma colher, dessas de sopa que fala, dessa grandona, essa que eu como, feijão também sempre, sempre tem alguma salada, é... e sempre tem que tê uma carne né, se nãonão dá... (risos) Triste, eu comi um croissant de frango, só não bebi nada e ainda catchup e maionese pra detonar. (Entrevistada 10).

A composição do almoço descrita pelos entrevistados também foi observada por Abdala ${ }^{16} \mathrm{em}$ sua pesquisa com famílias que têm o hábito de almoçar fora de casa diariamente: "[...] a adoção do peso em restaurantes e sua grande aceitação parecem configurar uma cultura culinária local, exprimindo um conjunto de preferências que manifesta peculiaridades culturais nacionais, [...] pela escolha do arroz, feijão, carne e salada tradicionais, em vez do sanduíche...”. A mesma composição é apontada pelo Guia Alimentar Para a População Brasileira: ${ }^{13}$ preparações com feijão e arroz estão presentes na maioria dos almoços, o que demonstra a "realidade" da alimentação dos brasileiros.

Entre os entrevistados, $45 \%$ disseram ter o hábito de jantar comida de sal e $30 \%$ declararam substituir essa refeição por lanche. Quando estes últimos foram questionados sobre o que comem nesse horário, as respostas foram bem homogêneas, a maioria disse comer um lanche como pão com alguma coisa (patê, presunto e mussarela) e sanduíches de maneira geral ou macarrão instantâneo, geralmente acompanhado de suco ou leite. Os que não tomam lanche relataram comer arroz, feijão, carne e salada.

É... alimentos básicos mesmo de uma refeição como arroz, feijão, salada, carne não, no horário da janta eu sempre faço um lanche mais reforçado, geralmente sanduiche natural ou então pizza, sei lá algum tipo de lanche. (Entrevistada 11).

Percebemos, porém, que alguns relatam jantar e quando descrevem o que consomem, falam em lanche. Portanto, pode haver a interpretação de que jantar é à noite e que nesse horário qualquer coisa que se consome é o jantar; ou este pode ser entendido apenas como a refeição dita completa; ou ainda há a possibilidade de pular esta refeição e chamar de lanche da noite, que seria o único momento de uma alimentação noturna.

Assim como Araujo \& Abdala, ${ }^{6}$ no trabalho sobre os hábitos alimentares de estudantes da Universidade Federal de Uberlândia, campus Santa Mônica, afirmaram que a maioria dos seus entrevistados tem preferência pela "comida de sal". Nos relatos que colhemos, notamos que a maioria também faz opção por arroz, feijão, carne e salada. Desse modo, não há indicação de substituição 
de uma refeição dita completa por um lanche no horário do almoço. Porém, essa substituição é claramente notada no horário do jantar, como já observado em estudo de Castro \& Abdala. ${ }^{9}$

Quando analisadas as escolhas ao longo do dia, percebe-se que pode haver um deficit de grupos alimentares, como o das hortaliças, que quando citadas nas preparações de saladas, são colocadas apenas uma ou duas de preferência. Nesse aspecto, segundo recomendações do Guia Para a População Brasileira,${ }^{13}$ as hortaliças são boas fontes de fibras, vitaminas, minerais e compostos bioativos que contribuem na prevenção de doenças. Recomenda-se acrescentar produtos in natura ou minimamente processados à alimentação, em grande variedade, principalmente de origem vegetal, que constituem a base para uma alimentação equilibrada do ponto de vista nutricional, com sabor agradável, culturalmente apropriada e que promove a produção sustentável tanto ambiental quanto social.

O tempo gasto para realizar o almoço, o local onde é feito e a companhia também podem interferir no valor nutricional da refeição. Preparações consumidas com atenção e sem pressa beneficiam a digestão dos alimentos e evitam que se coma além do necessário. Portanto, comer de forma regular, devagar e com atenção leva a um controle natural da quantidade que comemos. As características do ambiente onde fazemos nossas refeições, como o cheiro, sons, iluminação, conforto, limpeza, entre outras, influenciam a quantidade que comemos. E refeições feitas com acompanhantes evitam que se coma rápido, favorecem ambientes mais adequados por demandarem mesas e utensílios apropriados. ${ }^{13}$

Concordamos com essas observaçóes, pois a maioria dos entrevistados, mesmo relatando que o tempo gasto para realizar o almoço é suficiente, comentam que comem rápido e que quando acompanhados comem mais devagar, uma vez que durante a refeição aproveitam para conversar, seja para fazer a atualização de vivências cotidianas, seja conversando assuntos que dizem respeito à faculdade. Em um dos relatos acima citados, fica explícita a interferência das características do ambiente, pois os estudantes relataram consumir salgados quando o tempo é escasso ou insuficiente, e o fazem andando e conversando, ou então se sentam na lanchonete, com bastante barulho e agitação, e não comem direito. Em contrapartida, as refeições em casa eram realizadas em ambiente calmo e familiar.

\section{Considerações finais}

Neste estudo, analisamos o ato de comer propondo um diálogo entre Ciências Sociais e Nutrição, considerando que se alimentar envolve significações culturais e sociais que extrapolam a necessidade fisiológica. Nessa perspectiva, alguns aspectos se destacaram nos relatos dos universitários entrevistados, como a companhia, a duração da refeição, o ambiente e as escolhas dos alimentos. 
A maioria dos entrevistados prefere estar acompanhada durante o almoço. A sociabilidade, nesse momento, se relaciona à distração, conversa com os amigos e assuntos que dizem respeito à universidade. Quando há companhia, as escolhas recaem sobre opções mais saudáveis, uma vez que há influência na decisão de onde e do que comer. Desse modo, quando acompanhadas, as pessoas preferem a "comida de sal" - a maioria indicou opção pelo arroz, feijão, carne e salada. Apenas 10\% apontaram substituição do almoço por um lanche rápido, devido à pressa ou ausência de companhia. Em contrapartida, no jantar essa substituição é comum.

A companhia também influencia a duração da refeição, em geral de 20 minutos, podendo chegar a 50 minutos. No entanto, ela não é a única variável que interfere nesse fator, pois algumas pessoas destacaram que há pouca disponibilidade de tempo, devido ao grande número de atividades e a horários limitados para o almoço.

Ambiente é um dado importante. Neste estudo, sua influência foi citada em especial por pessoas que recorrem a lanches rápidos e criticaram os lugares que os oferecem no campus e seu entorno. Esses foram avaliados como comumente barulhentos, agitados e com pouca disponibilidade de assentos, contribuindo para maior rapidez na permanência e no consumo do alimento. Nesse aspecto, concordamos com os entrevistados por Araujo e Abdala, ${ }^{6}$ que apontaram a necessidade de ampliação dos espaços de convívio nos campi da universidade, para que os discentes possam reforçar seus momentos de sociabilidade durante e após as refeições e atividades.

Outro fator relevante diz respeito às escolhas dos alimentos. Notamos pouca variação no grupo das hortaliças, quando comparamos à recomendação de consumo diário de ampla variedade de verduras e legumes in natura, tanto por razões relativas a benefícios nutricionais, quanto por questões de ordem cultural, ambiental e social. ${ }^{13}$

Entendemos, desse modo, que se trata de promover políticas e espaços no interior da universidade, que contemplem amplas possibilidades de informação e divulgação de recomendações para uma alimentação saudável, considerando-a como conjunto de fatores que não se restringe à questão nutricional, mas ao ambiente e à sociabilidade que o ato de se alimentar propicia.

\section{Referências}

1. Goldenberg M. Cultura e gastro-anomia: psicopatologia da alimentação cotidiana. Entrevista com Claude Fischler. Horizontes Antropológicos 2011; 17(36):235-256.

2. Maciel ME. Cultura e alimentação ou o que têm a ver os macaquinhos de Koshima com BrillatSavarin? Horizontes Antropológicos 2001; 7(16):145-156.

3. Poulain JP. Sociologias da alimentação: os comedores e o espaço social alimentar. Florianópolis: Ed. UFSC; 2004 
4. Canesqui AM, Diez-Garcia RW, organizadores. Antropologia e nutrição: um diálogo possível. Rio de Janeiro: Editora Fiocruz; 2005.

5. Almeida M, Guimarães T, Freitas MC, Sampaio L, organizadores. Escritas e narrativas sobre alimentação e cultura. Salvador: EDUFBA; 2008.

6. Araujo SAS, Abdala MC. A desconstrução de hábitos alimentares entre jovens universitários. In: IX Encontro Interno, XIII Seminário de Iniciação Científica -Semana Nacional de Ciência e Tecnologia; 2009; Uberlândia. 10 p.

7. Rial CSM. Fast-food: a nostalgia de uma estrutura perdida. Horizontes Antropológicos 1996; 2(4):94103.

8. Alves HJ, Boog MCF. Comportamento alimentar em moradia estudantil: um espaço para a promoção da saúde. Revista Saúde Pública 2007,41(2):197-204.

9. Borges CM, Lima Filho DO. Hábitos alimentares dos estudantes universitários: um estudo qualitativo. In: Seminário em Administração; 10-11 ago. 2004; FEA-USP. 11 p. [acesso em: 20 jan. 2014]. Disponível em: http://www.ead.fea.usp.br/Semead/7semead/paginas/artigos\%20recebidos/ marketing/MKT37_-_H\%E1bitos_Alimentares_dos_Estudantes_Uni.PDF

10. Castro LA, Abdala MC. Televisão no momento das refeições. Horizonte Científico [Internet]. 2011; 5(2):1-27. [acesso em: 20 jan. 2014]. Disponível em: www.seer.ufu.br/index.php/horizontecientifico/ article/view/6249

11. Queiroz MIP. Relatos orais: do “indivizível” ao “divizível”. Ciência e Cultura 1987; 39(3):272-286.

12. Poulain JP, Proença RPC, Diez-Garcia RW. Diagnóstico das práticas e comportamentos alimentares. In: Diez-Garcia RW, Cervato-Mancuso AM, organizadores. Mudanças alimentares e educação nutricional. Rio de Janeiro: Guabanara Koogan; 2011. p. 149-161.

13. Brasil. Ministério da Saúde. Secretaria de Atenção à Saúde. Departamento de Atenção Básica. Coordenação Geral da Política de Alimentação e Nutrição. Guia alimentar para a população brasileira. Brasília: Ministério da Saúde; 2014.

14. Galante AP, Galisa MS, Ribeiro SML. Recomendações nutricionais para uma alimentação equilibrada. In: Silva SMCS, Martinez S. Cardápio: guia prático para elaboração. 2. ed. São Paulo: Roca; 2008. p. 21-26.

15. Gambardella AMD, Frutuoso MFP, Franchi C. Prática alimentar de adolescentes. Revista de Nutrição 1999; 12(1):5-19.

16. Abdala MC. Da casa ao restaurante. Representações sobre o comer fora em Minas Gerais. In: Montebello N, Collaço JHL, organizadores. Gastronomia: cortes e recortes II. Brasília: Senac; 2007. p. 52-69.

Recebido: 14/4/2015

Revisado: 06/5/2015

Aprovado: 28/6/2015 